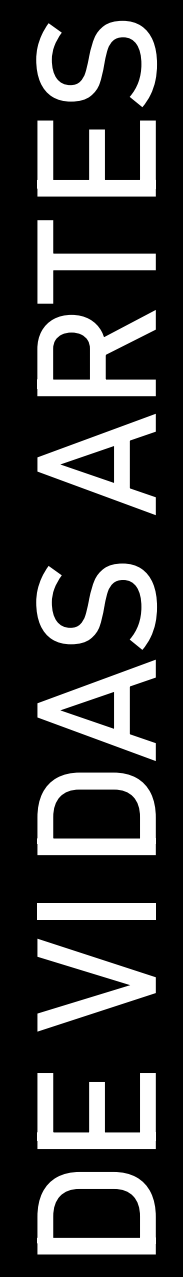

PAULA GUERRA E LÍGIA DABUL (EDS.) 


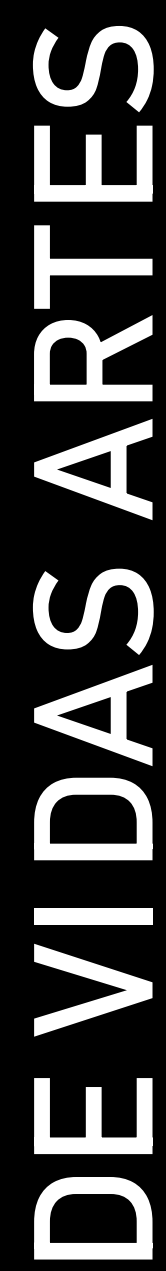

\section{PAULA GUERRA E LÍGIA DABUL (EDS.)}

Design por Irandina Afonso

Ilustração da Capa por Lua Celina

Publicado em Setembro 2019

Universidade do Porto. Faculdade de Letras

[University of Porto. Faculty of Arts and Humanities]

Porto, Portugal

ISBN 978-989-8969-18-7

Suporte: Eletrónico - Formato: PDF / PDF/A 


\title{
III.2. Manifestações artísticas alternativas ou a face visível de um Portugal contemporâneo
}

\section{III.2. Alternative artistic manifestations or the visible face of a contemporary Portugal}

\section{Susana Januário}

\begin{abstract}
Resumo
O nosso contributo resulta da necessidade de refletirmos em torno do objeto de estudo da investigação que nos encontramos a desenvolver. Está a considerar-se manifestações/iniciativas artísticas compreendidas genericamente como alternativas/underground, cuja emergência assenta designadamente em lógicas doit-yourself, que se materializam como multi/transdisciplinares artisticamente e se baseiam no pluralismo e experimentação. A consolidação destas manifestações no Portugal contemporâneo implica uma discussão dos conceitos inerentes à sua problematização enquanto objeto de estudo. Da reflexão encetada e aqui partilhada, procura-se demonstrar a sua operacionalização aproximada através de um breve mapeamento das manifestações artísticas em estudo, a partir da análise de conteúdos produzidos por um conjunto de dispositivos mediáticos.
\end{abstract}

Palavras-chave: manifestações artísticas, subcampo artístico alternativo e underground, mapeamento.

\begin{abstract}
Our contribution results from the need to reflect on the object of study of research that we are developing. We are considering artistic manifestations/initiatives generally understood as alternatives/underground, whose emergence is based on do-it-yourself logics; they are materialized as multi/transdisciplinary art and they are based on pluralism and experimentation. The consolidation of these manifestations in contemporary Portugal implies a discussion of the concepts which are inherent to its problematization as object of study. From the reflection initiated and shared here, we try to demonstrate, from the analysis of contents produced by a set of media devices, an approximate operationalization through a brief mapping of the artistic manifestations.
\end{abstract}

Key words: artistic manifestations, alternative and underground artistic subfield, mapping.

\section{Breviário reflexivo de objetos e intenções: os "limites da nossa arte"}

"A arte tem valia porque nos tira daqui" - Fernando Pessoa

Se a "arte nos tira daqui", para onde nos projeta? Neste caso, inevitavelmente, para o seu usufruto - uma vez não sendo artistas nem agentes ativamente envolvidos no campo artístico - e para a sua compreensão. E as duas coisas 
acontecem, não por acaso, mas porque se interrelacionam, uma vez que não podemos dicotomizar as dimensões que nos constituem: experiência comum e conhecimento retroalimentam-se e permitem o surgimento do interesse, do motivo e do gosto que se constitui como nutriente fundamental de qualquer investida. A investigação que estamos a levar a cabo surge, precisamente, por razões pessoais e por razões profissionais; um acaso que se transformou num desafio materializado na investigação que estamos a desenvolver há praticamente dois anos ${ }^{157}$.

Aqui procuramos apresentar de forma reflexiva o nosso objeto de estudo, evidenciando as preocupações concetuais que nos surgem à medida que aprofundamos a teoria e imergimos no terreno. A concetualização necessária do objeto de estudo constitui um dos mais significativos desafios que enfrentamos, exponenciado pela intencional dialógica que estabelecemos entre teoria e prática. É parte do resultado deste enfrentamento que, neste momento, procuramos dar conta.

A nossa intenção inicial visava a compreensão de um conjunto de "atores"/"ambientes" /"cenas" cujas iniciativas - inscritas territorialmente resultam como impactantes particularmente ao nível do cruzamento de artes, processos, dimensões, identidades e territórios, constituindo potencialmente um subcampo artístico e cultural específico. Uma intenção que viria a materializar-se no estudo de iniciativas artisticamente multi/transdisciplinares que remetem para o pluralismo, a experimentação e o ecletismo de formas e discursos artísticos. Isto é, um conjunto de iniciativas que, decorrentes dos processos de democratização, festivalização da cultura e de cosmopolitização artística, que se assiste em Portugal a partir da década de 1980, se consubstanciam em manifestações artísticas que corporizam novas formas de criação, mediação, receção, e que aventam novas convenções/canonizações. São nestas que se substantifica a sua força simbólica de autoridade cultural, e nos termos do cultural turn (Chaney, 1994), uma vez invertidas as formas clássicas de classe, comunidade e tradição.

Explicadas e compreendidas, genericamente, como alternativas e/ou underground, ou ainda como informais, autónomas ou independentes (Jürgens, 2016), a emergência destas manifestações assenta em lógicas do-

\footnotetext{
${ }^{157}$ Enquadrada no programa de Doutoramento em Sociologia na Faculdade de Letras de Universidade do Porto e ao abrigo de uma bolsa de doutoramento da FCT - Fundação para a Ciência e Tecnologia e sob a orientação científica da Professora Doutora Paula Guerra.
} 
it-yourself (DIY), nas quais os artistas/criativos assumem, nomeadamente, papel de produtores/gestores, e os gatekeepers e os processos de criação de reputações surgem como fundamentais na provisão/atração/fruição destas

atividades. É precisamente na necessária tarefa de delimitação concetual do nosso objeto de estudo que assentamos uma das nossas principais fontes de desafio, não querendo incorrer na indeterminação e na inexatidão da expressão das representações sobre a realidade que pretendemos alcançar. O que nos faz discutir sobre o mais adequado enquadramento e respetiva concetualização do objeto de pesquisa advém de algum desvanecimento da precisão de alguns dos epítetos considerados, tendo em conta que qualquer determinismo ou delimitação concetual rígida resulte numa impossibilidade na realidade contemporânea. Vivemos um tempo e espaço de invasões, cruzamentos e multi/transdimensionalidade que nos coloca no desafio de apreender e compreender uma realidade de dinâmica hiperacelerada e de contornos tendencialmente pouco precisos ou determinados. A incursão no terreno tende a comprovar a necessidade de manter em aberto a discussão em torno do objeto de estudo que elegemos.

O que procuramos é explicar e compreender manifestações artísticas em espaços (semi)públicos urbanos catalisadores de um subcampo artístico emergente no Portugal contemporâneo. Ou seja, e conforme afirmado anteriormente, está a considerar-se manifestações que cruzam artes, saberes e disciplinas tradicionalmente menos consagrados pelo cânone artístico (Bourdieu, 1996), assinaláveis devido ao seu crescente hype quotidiano e mediático. O projeto encetado intenta conferir-lhes visibilidade e demonstrar a sua importância na contemporaneidade.

A reflexão que aqui partilhamos resulta do trabalho teórico levado a cabo e do trabalho empírico realizado até ao momento. Procuramos, assim, apresentar alguns apontamentos assumidos como esquissos concetuais assentes na dialógica enunciada, tendo por referência algum do trabalho empírico já realizado.

\section{Arte e cultura na contemporaneidade: do enquadramento à veleidade da precisão}

A incursão no terreno, mormente no trabalho de campo, tem-nos permitido um permanente questionamento relativamente ao esforço concetual que empreendemos em torno da realidade que pretendemos estudar. Da dialógica 
empreendida resulta estar-se perante um cruzamento de aspetos, processos e características que nos remetem para lógicas de ação social confundíveis, onde as linguagens e estratégias nos conduzem à inevitabilidade da hibridização que caracteriza a contemporaneidade (Latour, 1994).

Não obstante a imposição da hibridização nos leva a reconsiderar, conforme já sobejamente afirmado pelos mais diversos pensadores das mais diferentes áreas, as delimitações clássicas relativas à produção e usufruição cultural (assentes por exemplo nas dimensões de classe e tradição), não nos parece plausível deixar de problematizar o objeto de estudo. É em Bourdieu, Becker e Crane que encontramos as perspetivas estruturantes para delimitarmos o nosso objeto à dimensão cultural/artística.

Os contributos de Bourdieu (1996) na análise da arte e da cultura são incontornáveis quando se coloca a questão de se procurar delimitar um subcampo artístico diferenciado. A noção de campo enquanto espaço relacional conflitual entre as posições existentes nesse espaço, de acordo com regras/princípios específicos (Bourdieu, 2003), é particularmente relevante para a delimitação da realidade em estudo. Efetivamente, o campo artístico distingue-se dos demais pelo valor (simbólico) da arte em si (arte pela arte), dimensão fundamental para conferir autonomia e independência do campo artístico/cultural relativamente aos outros campos, designadamente ao económico. A noção de campo mantém-se profícua no intento de delimitação do espaço social que se pretende compreender, ao pugnar pela sistematicidade das ações entre determinados atores com fins, lógicas e dinâmicas comuns que, a par do elemento de troca que o carateriza - valor simbólico - permite-nos almejar a necessária distinção e diferenciação. Não obstante esta significância, a proposta desenhada por Bourdieu (1996) no se refere ao campo artístico/cultural não enquadrará o que, seguramente, o autor considerou não ser próprio do campo artístico, ou seja, o que compromete a sua autonomia e especificidade - a hibridização e se quisermos a invasão de outros valores de troca nas dinâmicas que se estabelecem no seu seio.

As interdependências entre as várias dimensões sociais, a par dos processos de hibridização numa dinâmica de crescente e acelerada consolidação, provoca a necessidade de equacionarmos o objeto do nosso estudo como um art world (Becker, 1984). Para Becker, a arte é perspetivada como um mundo social como qualquer outro; um art world é visto como sendo um grupo de pessoas que cooperativamente se organizam e convencionam 
fazer algo em conjunto (atividades/produtos que são por elas considerados artísticos). Rompendo com a clássica e tradicional sociologia da arte centrada no artista e no trabalho artístico -, a abordagem de Becker incide na rede de cooperação entre os indivíduos como central na análise da arte enquanto fenómeno social. Em cada art world existem convenções conhecidas e partilhadas por todos os membros da sociedade no qual ele (art world) existe, de modo a organizar a própria cooperação entre os participantes (Becker, 1984: 42). Estamos, portanto, perante crenças coletivas que estruturam a ação e determinam a forma da prática artística, o que indicia uma certa estruturação dos próprios art world.

$\mathrm{Na}$ linha do art world, Diana Crane defende a impossibilidade de compreender as diferentes formas culturais apartadas dos contextos nos quais são produzidas e consumidas, procurando incidir na complexidade crescente das formas como os vários tipos de diferenciação social afetam o consumo cultural, os quais não correspondem às tradicionais noções de alta cultura e cultura popular (Crane, 1992). A relação entre produção e usufruição (consumo) é explicitamente assumida na proposta de Crane. Dirime-se a tradicional distinção entre alta cultura e cultura e públicos, particularmente da TV e publicidade (cultura massificada), começando a definir-se estilos de vida em vez de classes. Da abordagem integrada das perspetivas sobre a cultura de classe, a media culture e a produção de cultura, a autora propõe uma conceptualização de cultura em três domínios, nos quais diferentes tipos de organizações produzem e disseminam cultura: (i) o core domain - dominado por conglomerados que disseminam a cultura por audiências nacionais e internacionais, aos quais estão expostos todos os membros de uma população (sendo a televisão o meio com maior significado neste âmbito); (ii) o peripheral domain - no qual dominam as organizações que disseminam a cultura numa base nacional mas distintiva em termos de subgrupos, geralmente demarcados pela idade e estilos de vida (tome-se como exemplos neste âmbito as editoras de discos e livros e as revistas); (iii) a urban culture - a produção e disseminação de conteúdos culturais ocorrem em contextos/cenários urbanos e dirigidos a audiências locais, a partir de organizações locais, constituídas no seio de redes culturais (subculturas e mundos da arte), as quais acabam por ser, sobejas as vezes, fontes de novas ideias e, eventualmente, a vir a alcançar a arena cultural, espaço anteriormente confinado à alta cultura - que ganha relevo ao passar a ser o 
que estabelece standards para cultura e formas do gosto popular; este último domínio carateriza-se ainda pelo facto de a produção dos trabalhos artísticos/culturais constituírem uma atividade social na qual os criadores culturais constantemente olham para outros criadores para validarem as suas próprias conceções estéticas e aspetos políticos.

Para Bauman (2013), a cultura - e a sua esfera artística em particular - é modelada de modo a ajustar-se à liberdade de escolha e responsabilidade pela escolha, assumindo como função a garantia de que essa escolha seja uma necessidade contínua e de que a responsabilidade pela mesma recaia na medida da condição humana líquida-moderna - no indivíduo. Questiona o autor se a individualização não será uma conveniente parangona da elite dominante, "que projeta no indivíduo a ilusão da possibilidade de se autorrealizar?" (Bauman, 2013: s/p). Para o autor, a função da cultura - dada a transversalidade da lógica e dominância de mercado - é criar necessidades, uma vez que as mantém irrealizadas, neutralizando a satisfação total e definitiva. A cultura esvanece-se, suprime-se na sociedade contemporânea, nas qual as redes substituem as estruturas e "em que o jogo interminável de conectar-se e desconectar-se dessas redes, um sequência inacabável de conexões e desconexões, substitui a determinação, a lealdade e o pertencimento" (Bauman, 2013: s/p).

Ao adensamento das abordagens corresponde a intensidade "desconcertante" da realidade apontada por Crane (1992) relativamente às culturas urbanas que designou por culture worlds. A composição destes mundos da cultura assenta em elementos transversais que apontam para: (i) os criadores culturais e o pessoal de suporte que os assiste (evidencia-se a lógica cooperativa apontada por Becker na produção do objeto artístico); (ii) as convenções partilhadas sobre o que devem ser/são os produtos culturais; (iii) os gatekeepers (críticos, curadores, editores), ou seja, quem avalia os produtos culturais; (iv) as organizações nas quais acontecem as atividades ou são produzidos e/ou exibidos os produtos culturais (galerias, teatros, museus, bares, revistas, etc.); (v) as audiências/públicos cujas caraterísticas podem constituir um fator determinante nos tipos de produtos culturais que venham a ser exibidos ou vendidos numa configuração urbana particular.

Daqui resulta uma panóplia diversificada de culturas urbanas, cuja forma como são perspetivadas pela autora nos permite enquadrar o nosso objeto de estudo. Algumas destas culturas, ora (i) são criadas em contextos 
de redes sociais informais de criadores e consumidores (partindo-se do pressuposto de que criadores e consumidores regulares de um determinado tipo de cultura tendencialmente conhecem-se e interagem uns com os outros, dominando as convenções), ora (ii) organizam-se em torno de pequenos negócios lucrativos (o foco das atividades dos criadores torna-se a organização e o objetivo é produzir trabalho que agrade à audiência) ou, ainda, (iii) se estruturam em torno de organizações não lucrativas, que visam preservar o património artístico e as tradições étnicas e não a criação de novas produções.

A nossa intenção, portanto, assenta no estudo de manifestações urbanas - passíveis de consubstanciar um subcampo artístico - que têm vindo a pautar a cena cultural portuguesa, pautada na atualidade na diversidade e a heterogeneidade de meios/recursos/mercados, ou seja em iniciativas que assentam (i) na noção de densidade relacional artística e aglomeração de stakeholders (Costa, 2001; Fortuna \& Leite, 2009; Silva et al, 2013), (ii) em práticas e processos sustentados em lógicas do-it-yourself (DIY), nas quais os artistas/criativos assumem 0 papel de produtores/gestores, etc. (Guerra e Quintela, 2016), (iii) em núcleos/nós de convivialidade (e de sociabilidade/socialização) (Jauss, 1990), (iv) cujos atributos físicos/materiais dos espaços em que ocorrem poderem condicionar as atividades e os processos criativos e (v) perante as quais o papel dos gatekeepers se assoma como fulcral nos processos de criação de reputações e na provisão/atração/fruição destas atividades (Silva et al, 2013, 2015; Guerra e Costa, 2016; Crane, 1992).

Até ao momento conseguimos - pensamos nós - ter matéria de facto que nos permite, de certa forma, enquadrar o nosso objeto de estudo. Impõese-nos precisar elementos que possibilitem a sua delimitação.

\section{Manifestas impressões de manifestações artísticas contemporâneas}

Incidimos o nosso objeto de estudo, como já referenciado, em manifestações artísticas inicialmente explicadas e compreendidas como alternativas e/ou underground, que corporizam novas formas de criação/mediação/receção/convenções/canonizações. O alternativo surge como conceito basilar para a apreensão do tipo de manifestações que, no conjunto, formarão um subcampo artístico. 
O paralelismo que referenciamos entre alternativo e underground não é casuístico, antes representa a proximidade dos termos/conceitos, se reservarmos, por direito, uma essência alternativa ao underground, uma vez que remete para a rutura, dissidência, diferenciação em relação ao instituído nas mais diferentes dimensões; na arte e na cultura rompe-se com o mainstream e as imposições a si inerentes. Numa dimensão mais purista do conceito - que de certa forma radica nas abordagens incidentes nas subculturas e culturas juvenis - considera-se o conjunto de estilos, expressões e movimentos que estão à margem dos circuitos padrão, comerciais e dos meios de comunicação de massa (Guerra \& Straw, 2017; Guerra, 2013).

Jürgens (2016) propõe e discute alguns conceitos sobre a realidade que se pretende estudar, tanto mais que algumas das iniciativas/manifestações paradigmáticas que suscitaram a nossa atenção constituem objeto de análise da investigação levada a cabo pela autora. Estamos a considerar termos como "alternativa", "independência", "autonomia" e "informalidade" para se compreender uma ação (social, cultural) que afetou os "regimes de produção, de mediação e receção do fenómeno artístico" (Jürgens, 2016: 19). O primeiro é interpretado por nós como a charneira do que se procura corporizar, aos quais se associam os restantes no sentido de lhe conferir maior sustentação e fundamento.

A independência artística remete-nos para a modernidade e as possibilidades que abre, nos séculos XIX e XX, para a emergência de novos movimentos expressivos e estéticos em rutura com a academia e o salão. Surgem condições para que apareçam exposições privadas e independentes ao sistema vigente. A disrupção impõe-se como marca indelével destas movimentações. Por seu turno, equacionar-se a autonomia artística implica que estejamos a considerar as ações que se constituem em estratégias que transgridem as assentes ora nas lógicas do Estado ora do mercado (galerias). A alternativa - que enquanto movimento se pode situar o seu início historicamente na década de 1960 - resulta das ações que surgem como críticas ao sistema institucionalizado da arte, que se materializam em estruturas/espaços coletivos de produção/mediação/receção artísticas. Ainda, entenda-se por informalidade o que se refere a projetos cujos artistas optam pela autogestão (sendo simultaneamente curadores) e por práticas artísticas e/ou de curadoria de caráter experimental (Jürgens, 2016). 
Apesar de estarmos perante um exercício de precisão concetual que nos permite clarificar os termos em apreço, consideramos, como já o dissemos, que o conceito de "alternativa" - inclusive se o retivermos como referência a um movimento artístico e cultural cuja a emergência é demarcada histórica e socialmente - acaba por ser o agregador dos outros, ainda que não necessariamente em concomitância. Vejamos:

o conceito de alternativa, termo que nos situa perante alguns núcleos e esferas de atuação artística emergentes no final dos anos sessenta e princípio dos anos setenta, resultado de um processo radical e generalizado de interrogação do instituído e do normativo, com repercussões na constituição de uma rede ampla de organizações e estruturas a partir das quais se alteram práticas, teorias, modos de produção e formas de fazer inscritas nas definições existentes de produção criativa e de circulação e instalação dos trabalhos artísticos (Jürgens, 2016:177).

Podemos facilmente discernir que o que está aqui em questão é a necessidade de ultrapassar ou romper com uma determinada vigência normativa institucionalizada (necessidade de independência face ao sistema instituído), criando novos modos (materializados em espaços e estruturas) de produção e circulação de trabalhos artísticos, onde se expresse uma vontade inequívoca de autonomia (face aos mecanismos e meios de legitimação artística, como os museus, as galerias ou mesmo à generalização do mercado corporizado pelas indústrias criativas) e se manifeste outras possibilidades, desta feita, assentes em dinâmicas não formais, de autogestão, abertas ao experimentalismo (informalidade). No âmago desta informalidade (e obviamente inerente ao que pode entender-se como alternativo) encontra-se o princípio do Do-it-yourself (DIY), algo "fundamental para a emergência de experiências de artistas (...) e também o caráter interdisciplinar que caracteriza muita da atividade dos espaços artísticos alternativos" (Jürgens, 2016: 211).

Os conceitos que aqui se discutem não são, atualmente, de pacífica aceitação, uma vez - parece-nos - já afetados pelo processo de hibridização referenciado; como se pôde verificar o termo "alternativa artística" poderá ser considerado pouco válido uma vez datado enquanto movimento, ou de difícil precisão concetual numa contemporaneidade caracterizada pela fluidez (Bennett \& Guerra, 2019).

Ainda que se possa considerar o movimento alternativo datado, as caraterísticas que se lhe associam permite-nos enquadrar a emergência, em Portugal nos anos 1990, de iniciativas que procuravam romper com as lógicas subjacentes ao sistema de legitimação institucional, assumindo-se como 
experimentais, autogeridas, informais e assentes nos princípios DIY (Jürgens, 2016). Algumas destas iniciativas ainda se mantêm hoje, constituindo-se como elemento inspirativo para as que Ihe sobrevieram já durante o novo milénio.

Efetivamente a complexificação social em geral e do campo artístico e cultural em particular contribui para adensar a discussão em torno do conceito de alternativo. Tanto mais quanto nos deparamos com o facto de algumas destas manifestações se demarcarem no campo artístico, sendo reconhecidas no âmbito da legitimação e consagração artísticas. Aos processos de informalidade sucedem-se dinâmicas formalizadas de curadoria e o reconhecimento no campo artístico. A comunicação social - quer através das agendas/roteiros que integram, quer através de reportagem/notícia assume, neste âmbito, um papel duplo: o de divulgação e de contributo para o reconhecimento social da iniciativa. Retomaremos o assunto; por ora, consideramos pertinente retermo-nos nas representações de alguns agentes/atores associados aos casos que estamos a estudar de forma mais intensiva.

No que respeita ao "alternativo" e "underground":

\begin{abstract}
Eu não gosto nada que nos chamem espaço alternativo, porque realmente a gente não alterna coisa nenhuma. Nós estamos... Nós somos... Eu gosto da palavra intermediário ou intermédio... Nós estamos... Eu sou fotógrafo... a escala de cinzentos vai do preto, tá lá em cima, o branco está cá em baixo, no meio disto tudo há uma data de cinzas, vamos dizer que o preto é museu e que o branco é a galeria, o XXXX é o espaço entre essas duas grandes entidades e que faz falta nesta cidade, como faz falta em qualquer cidade do planeta (...). É como teres (...) a Casa da Música e teres Serralves um ao lado do outro, só existir isso... tem de existir uma brecha, não é? Nas brechas é que existe... é nas caves que existem essas coisas, é nesse espaço intermédio. Fundador(a) de manifestação artística em estudo - fevereiro de 2019).

Há um sempre um momento... Há um momento que eles ainda não estão a trabalhar para a galeria e muito menos para o museu, não é? Ainda estão a conquistar a sua posição no campo, enquanto isso acontecer, eles estão no underground e isso... O que é que o XXXX vai estar a fazer? Viabilizar que eles conseguem produzir (...). Portanto, a questão aqui é - como é que nós viabilizamos estes espaços, damos-lhes condições "ok, a gente paga-te um mês de residência, dá-te os materiais, dá-te a oficina da arte, que aquilo está meio parado, fazemos os acordos todos contigo, damoste o cunho branco onde tu podes não sei quê, damos-te a cama..." E agora, isto ainda é underground? Ainda é do-it-yourself? (...) Não sei... Eu acho que hoje em dia é muito difícil tentar dentro da arte contemporânea ter essa definição de underground. (Agente_3 de manifestação artística em estudo - fevereiro de 2019).
\end{abstract}

Em relação à legitimação, reconhecimento e processos tendencialmente mais formalizados: 
O XXXX onde tu realmente começas a ganhar alguma legitimidade, num espaço de legitimação, onde permite realmente dizer "ok, dependendo da tua execução, tu vais ter feedbacks para poderes continuar e ser bom ou não e se for um desastre, olha, desistes, ok, mas ao menos...

Nas Artes Plásticas (...) como é que é feita a programação? Nós convidamos curadores, nós só somos curadores de curadores! (...) A gente tem dois momentos ao ano, ou três, em que abrimos candidaturas para seleção de projetos onde fazem o júri... não quero eu nunca ser barómetro... (Fundador(a)_3 de manifestação artística em estudo - fevereiro de 2019).

Eu sou o resultado das minhas vivências e das minhas relações pessoais e profissionais. Portanto, em 2011, eu já tinha um aporte de relações profissionais com artistas e com a arte em si e depois, na parte da produção, ajudou-me imenso o facto de eu (...) gerir equipas técnicas de produção de obra (...). Portanto, eu tenho uma coisa que pouca gente tem em Portugal, que é a capacidade de fazer a programação artística e capacidade técnica de executar projeto; normalmente estão sempre em cabeças diferentes de produção. (Fundador(a)_1 de manifestação artística em estudo janeiro de 2019).

Uma das questões que se coloca a este tipo de iniciativas/manifestações tem que ver com a sua sustentabilidade, conferindoIhes uma dimensão de efemeridade (algumas deixaram de existir) perante 0 desafio da independência (face ao Estado e/ou mercado). A independência nuclear na sua emergência tende a esvanecer-se em favor da manutenção da existência. Mais, a questão das indústrias culturais e o entretenimento associado provoca o reposicionamento das iniciativas não só no que se prende com a independência, mas também com a autonomia. A fidelização de públicos e a dependência do seu próprio reconhecimento no espaço (ou campo) social em que se integram levanta, uma vez mais, a questão da necessidade de reconfiguração e hibridização.

É muito simples. Uma empresa, o objetivo é fazer dinheiro; a associação, não! E a gente junta aqui as duas coisas. A empresa é um espaço de liberdade, a associação não (...). A associação é o espaço que agrega as pessoas no projeto comum e é o braço cultural do XXXX e o XXXX é o braço comercial da associação. Isto é de muita complexidade. Isto é muito complexo $(\ldots)$. A gente tenta gerir isto como uma empresa, como uma empresa tem vários turnos, vários horários, as pessoas... (...) [por seu turno, a associação] só existe porque vai à DGArtes buscar dinheiro $(\ldots)$. 0 ano, quando a gente esteve para não ter o apoio da DGArtes, nós realmente vimos que realmente íamos estar muito mal. (Fundador(a)_3 de manifestação artística em estudo - fevereiro de 2019).

Aí, nós começámos a fazer o apoio diretamente ao município, à Câmara Municipal, que tem um modelo de financiamento das associações culturais; portanto, nós estamos num grupo de associações que pedem apoio (...); portanto, nós em conjunto com todas as outras associações e em pé de igualdade, apresentamos a nossa candidatura e fazemos o nosso pedido; e depois temos também os apoios particulares, neste caso, temos ainda só um e como organização, um bocado se calhar por preguiça nossa... também não 
nos temos... também não temos ninguém com este perfil comercial... acabamos por ser todos artistas e não há ninguém que pegue nesse papel assim muito a sério, mas gostávamos de ver o XXXX a ter mais alguns patrocinadores, acho que poderíamos fazer mais e o que fazemos um bocadinho melhor até (...). (Fundador(a)_2 de manifestação artística em estudo - fevereiro de 2019).

Apesar da complexidade da realidade que pretendemos apreender, consideramos a existência de um conjunto de elementos, fatores, processos e dinâmicas que nos permitem adiantar algumas dimensões que contribuem para a sua caracterização. Por seu turno, ao tomarmos como central a emergência das manifestações em estudo permite-nos assegurar alguma precisão, ainda que as mesmas se venham a reconfigurar e a distanciar da essencialidade e "purismo" inicial.

Assim, ainda que se possa relativizar ou mesmo por em questão o epíteto de alternativo, consideramos que parte da sua essência concetual se mantém, na medida em que existe um espaço social (artístico/cultural) entre a galeria e o museu que é preenchido por dinâmicas mais ou menos comuns que, ainda mais, sustentam um determinado tipo de arte, de artistas, iniciativas e eventos de confluência que estarão (pelo menos vamos procurar comprová-lo através das análise reticular das agendas e programação dos casos de estudo) na base da tese da existência de um subcampo artístico. Ainda, consideramos que o papel agregador que atribuímos a este termo se mantém perante as caraterísticas que passamos a enunciar de seguida, enquanto elementos estruturadores da realidade em estudo.

A base de experimentalismo artístico continua a ser marcador importante, permitindo não só a oportunidade aos artistas novos de criarem como divulgar as próprias criações artísticas. Esta permeabilidade à criação/criatividade constitui-se como uma dimensão social significativa. Este elemento democratizador é elemento diferenciador nas manifestações em estudo.

O XXXX onde (...) permite realmente dizer "ok, dependendo da tua execução, tu vais ter feedbacks para poderes continuar (...) ou não" (...); é o espaço da tentativa, é o espaço do erro, é o espaço de ensaio, espaço da experiência, o espaço onde as coisas não têm que estar acabadas, realmente tu podes não conseguir concretizar; ou seja, se estiveres numa residência artística e, se no final, o projeto for assim uma coisa incipiente, whatever, não estou minimamente preocupado! (Fundador(a)_3 de manifestação artística em estudo - fevereiro de 2019).

Mas se calhar situamo-nos ali numa fase de mais... nas origens das coisas, nos inícios; os artistas que têm interesse pelo XXXX não são artistas com grandes consagrações, embora nós temos participações de artistas que estão aí na Praça muito bem conceituados e que têm um percurso muito importante já, mas também essa participação no XXXX acaba, se calhar, de ser vista por eles 
como uma coisa mais experimental, mais descontraída. Ou seja, reforçando aqui que nós não estamos em oposição a outras formas, somos complementares e ocupamos um espaço (...). Mas sim, acredito que sim, existe espaço para artistas mostrarem os seus trabalhos desta forma informal (...). (Fundador(a)_2 de manifestação artística em estudo - fevereiro de 2019).

Os princípios e as lógicas de Do-lt-Yourself (DIY), associados a um modo de fazer revestido pela informalidade, assumem particular relevo (Guerra, 2018), tendo em conta que, apesar da necessidade de sustentabilidade - que gera dependências e formalidades -, as respostas aos desafios que são colocados a estas iniciativas/manifestações sustentam-se em estratégias criativas que por si se ancoram nestas lógicas e princípios DIY. $\mathrm{Na}$ verdade, os financiamentos nunca vão ser suficientes ou adequados (as contrapartidas nem sempre se coadunam com as pretensões, o que por si resvala na informalidade) para que se prescinda de um fazer criativo. Isto apesar do profissionalismo crescente que pauta o desempenho e respetiva oferta artística e cultural em Portugal (ICS -UL, 2014).

\footnotetext{
Sou um líder... mais espiritual [Risos] do que o chefão... ainda continuo a limpar sanitas, se for preciso... Mas vou para todas as áreas e as pessoas respeitam-me por isso, obviamente. Mas é por aí, por exemplo há 5 anos, quando montámos o Restaurante, abandonei a programação, dei a programação ao XXXX e disse "vou para a cozinha, vou para a cozinha um ano, não quero saber de músicos, não quero saber de artistas a ligarem-me, vou para a cozinha, vou trabalhar a massa, o pão, as massas (...) vou brincar" e pronto, montei o restaurante, com o objetivo de montar o restaurante, claramente $(\ldots)$. Mas a parte cultural... se não tiver esse risco... Tu agendas um músico, este concerto vai-me custar x, "oh pá, a bilheteria vai ser resvés Campo de Ourique, não sei se vamos conseguir fazer isto”... estás permanentemente, estás permanentemente... para quem é que se destina... para quem é que este concerto, para quem é que eu consigo dirigir isto, onde, que sítio, que canais,... (Fundador(a)_3 de manifestação artística em estudo - fevereiro de 2019).
}

A essência democrática destas manifestações no campo artístico evidencia-se pelo facto de criarem efetivamente oportunidades (de criação, mediação e receção) - a vertente experimental comprova-o a par da resiliência associada ao DIY -, por potenciarem o acesso à cultura e à arte e, ainda, por se assumirem muitas vezes como mobilizadores na defesa dos direitos humanos e combate às desigualdades sociais. Esta mobilização ora está patente de forma explícita - através de iniciativas/ações que se destacam na programação - ora implicitamente nos objetos artísticos. Muitas são as criações artísticas nas quais se manifesta de forma explícita preocupações da nossa contemporaneidade. 
Eu sempre achei que devíamos democratizar a arte e torná-la mais acessível à população e tirá-la dos nichos, a criação que normalmente é dita de nicho, porque eu acho que só assim se pode salvar a criação contemporânea. Porque só num entendimento e numa relação próxima com a criação artística e que as pessoas percebem - que é a importância da criação artística para a sua qualidade de vida global é que ela se pode salvar, porque se não fica sempre nos nichos e há um hiato muito grande, uma distância muito grande, uma não compreensão sobre o que é arte. (...) eu sinto essa responsabilidade quando estou a programar, de propor à minha população que pense sobre esta grande diversidade humana que existe no mundo e que existe aqui e que está tudo bem! Fundador(a)_1 de manifestação artística em estudo - janeiro de 2019).

Porque os bailarinos a uma dada altura interagiam fisicamente um com o outro... de um formato artístico que as pessoas nunca teriam contactado antes! Eu acho que este valor do XXXX é muito grande. Isto é um valor democrático! (...) De acesso aberto, democrático, livre... 0 conceito fundamental do XXXX ser um festival democrático, aberto a todos, para mim é excelente! Eu acho que esse conceito não deve mudar, acho que é uma riqueza grande no XXXX. (Agente_5 de manifestação artística em estudo - fevereiro de 2019).

Apesar de delimitarmos a nossa atenção investigativa a manifestações claramente multi/transdisciplinares, consideramos que o subcampo que procuramos apreender é caracterizado por manifestações/iniciativas que, per si, tendem a sê-lo. A liquidez que reveste a nossa contemporaneidade atravessa o campo artístico - é predominante o conjunto de iniciativas que, uma vez possuindo uma significativa vertente experimental, tendem para o cruzamento de disciplinas, ora como um mero apontamento (que associa por exemplo o som à imagem ou imagética da iluminação) ora como demarcações intencionais de transdisciplinaridade. Curiosamente, a tendência crescente do reforço do apoio estatal, entre 2013 e 2018, à área de "cruzamentos disciplinares" (DGARTES, 2018) comprovam-no.

Ainda, estamos a considerar manifestações cujos espaços - apesar de efémeros e/ou públicos em alguma delas - proporcionam importantes núcleos e nós de convivialidade (e de sociabilidade e socialização) essenciais para a difusão de informação, para o contacto e para a legitimação dos atores. Efetivamente, a localização das atividades culturais, e dos processos criativos em si, podem ser fortemente condicionados por atributos físicos ou materiais específicos dos espaços. Os agentes/atores não só reconhecem tal, como o assumem no âmbito das suas estratégias programáticas e de criação artística.

Muitas vezes eu quero fazer o contraste, num sítio mágico pôr música industrial, mas por intenção, não é por... eu nunca escolho um artista sem saber onde é que ele vai atuar. Ou seja, a minha 
parte de programação tem a ver com o tema e tem a ver com espaço onde ele pode atuar. (Fundador(a)_1 de manifestação artística em estudo - fevereiro de 2019).

\begin{abstract}
Primeiro tenho que render aqui o elogio à cidade de XXXX, porque acho que cria, que é cenografia perfeita e tem condições em termos de espaços e recetividade muito interessantes e acho que isso é um dos pontos que distingue bem; no fundo, podemos the chamar a paisagem, não há em mais lado nenhum, é nossa e acho que isso cria ali um ponto de distinção muito grande. Independentemente daquilo que as pessoas vão ver em termos artísticos e dos projetos, só este passeio pela cidade e o facto de poderem entrar nestes espaços, que normalmente estão fechados ao público, já só por si já é um ponto de interesse; porque (...) muita gente que vem visitar o XXXX (...) tem muito interesse em entrar nos espaços, circular, no fundo, viver um bocado o ambiente. (Fundador(a)_2 de manifestação artística em estudo - fevereiro de 2019).

Descobri este espaço (...) e depois, nesse momento, passamos a ter um projeto e um espaço. Um espaço todo abandonado, todo desfeito, um pouco. A metáfora do barco abandonado que se descobre e depois se sonha trabalhar nele para fazer uma viagem. Foi o que fizemos ao longo dos primeiros anos. (...) E, então, este espaço surge como atelier, espaço de trabalho de muita gente, espaço onde as pessoas vem beber um copo no final da tarde, espaço que vêm ajudar a raspar uma parede e a pintar uma sala e (...) abrimos ao público (...) para nos mantermos em funcionamento até agora (...). (Fundador(a)_3 de manifestação artística em estudo - fevereiro de 2019).
\end{abstract}

À questão do espaço físico no qual se engendra e exponencia um espaço social associa-se uma outra questão que atravessa o nosso tempo a da usufruição e valorização da experiência pessoal e coletiva. Os indivíduos tendem a procurar a usufruição da experiência e esta apela a mais do que o produto artístico em si, apela ao contexto, cuja vivência, de usufruição e apego, transforma a vivência numa cena. O conceito de cena atravessa também a nossa discussão concetual. Isto porque os públicos constituem uma parte significativa das iniciativas; a adesão e a subsequente fidelização dos mesmos transformam-nos em agentes ativos da manifestação e da sua própria continuidade. Este conceito revela-se como importante tanto mais quando existe uma forte relação do objeto de estudo com o espaço (social e territorial), com a organicidade reticular que 0 carateriza, com 0 alternativo/transgressor e o com sentido coletivo imanente. Estruturado a partir dos conceitos art world de Becker e de campo de Bourdieu (Bennett \& Peterson, 2004), o conceito de cena, emergido primeiramente de referências mediáticas às atividades culturais, surge no campo científico a partir dos anos 1990, através de Straw (1991) e das cultural scenes. Muito embora se parta dos ambientes musicais em torno do consumo de música, consideramos que este conceito, dada a sua plasticidade, é particularmente relevante para 
enquadrar a vivência cultural e artística atual. Consideramos pertinente, portanto, reter algumas caraterísticas que Blum (2001) atribui ao que se pode considerar como cena, a saber: a espacialidade (as práticas sociais são demarcadas por uma relação de reciprocidade com o espaço, mormente o da cidade/urbano); a coletivização (está-se perante sociabilidades intensas, sustentadas em interesses e gostos partilhados); a teatralidade (uma determinada forma de agir, como uma performance); a transgressão (o diferente e a quebra com o quotidiano); o espetáculo (incitamento a uma contínua visitação através de elementos de sedução, no sentido de impressionar e fascinar); a inter-relação (a relação inerente das cenas com outras cenas - aspeto particularmente importante para a demarcação conforme é nossa intenção - de um subcampo).

\footnotetext{
Vêm os netos dizer ao avô "é aqui que eu venho ver os concertos ao sábado, da banda que eu gosto" e querem fazer a visita guiada (...). (Fundador(a)_3 de manifestação artística em estudo fevereiro de 2019).

Há pessoas que vêm... Aliás, eu revi um colega meu de estudo de Coimbra, que a mulher - eles vivem em Coimbra - que a mulher dele expõe já há três anos no XXXX e eu não sabia e eles vêm, expõem todos os anos, gostam muito do festival; temos colegas de Lisboa a vir recorrentemente, temos pessoas que guardam o fim de semana para vir, muita gente $(. .$.$) que vai (.$.$) intencionalmente para$ ver o XXXX... sim! (Agente_5 de manifestação artística em estudo - fevereiro de 2019).

Vem muita gente de vários sítios. E há pessoas que vêm sem ser do cartaz. Ou seja, as pessoas já sabem.... Tenho vários emails de várias pessoas a pedir como é que são as datas este ano... ainda não lancei nada de programação... para marcarem férias. Já tem um público fiel, isso tem! Nacional e internacional. (Fundador(a)_1 de manifestação artística em estudo - fevereiro de 2019).
}

Esta reflexão resulta de um processo contínuo que nos acompanha desde a realização do projeto de investigação, o qual se tem enriquecido como procuramos demonstrar - à medida que imergimos no terreno e perscrutamos as representações dos atores/agentes envolvidos. Não obstante, seguindo uma intenção, revestida de alguma instintividade, procuramos imergir na realidade já com a finalidade de a constituir como subcampo. Assim, a partir da análise de conteúdos produzidos pelos média perscrutamos a incidência destas manifestações no território. A partir desta análise foi possível verificar algumas tendências hegemónicas inscritas no território no que respeita à "agenda cultural/artística" portuguesa e consequentes processos de criação/mediação/receção/canonização contemporâneos. 


\section{Um breviário das manifestações artísticas contemporâneas impressas no território}

A incidência analítica nos conteúdos dos media assenta num pressuposto inicial basilar associado à esfera mais simbólica do subcampo em estudo, fundamental para interpretar a aglomeração e a territorialidade das atividades culturais: o facto de os gatekeepers (neste caso os média) desempenharem um papel relevante quer nos processos de criação de reputações, quer na provisão e fruição das atividades.

A análise documental de conteúdos produzidos incide num conjunto de dispositivos mediáticos considerados relevantes no que respeita à produção/mediação/divulgação cultural e artística em Portugal ${ }^{158}$, entre 2007 e 2017. O registo da informação partiu da seleção de notícias/notas/reportagens que referem/respeitam a manifestações mencionadas como alternativas, a par das consideradas, no âmbito do processo exploratório levado a cabo durante a investigação, pelos atores/agentes privilegiados do subcampo em estudo. Da recolha da informação, que culminou em 849 ocorrências registadas, pode verificar-se que a maioria destas acontece em Lisboa; seguindo-se o Porto, ainda que o número de registos seja praticamente $1 / 6$ dos verificados em Lisboa (Figura III.2.1).

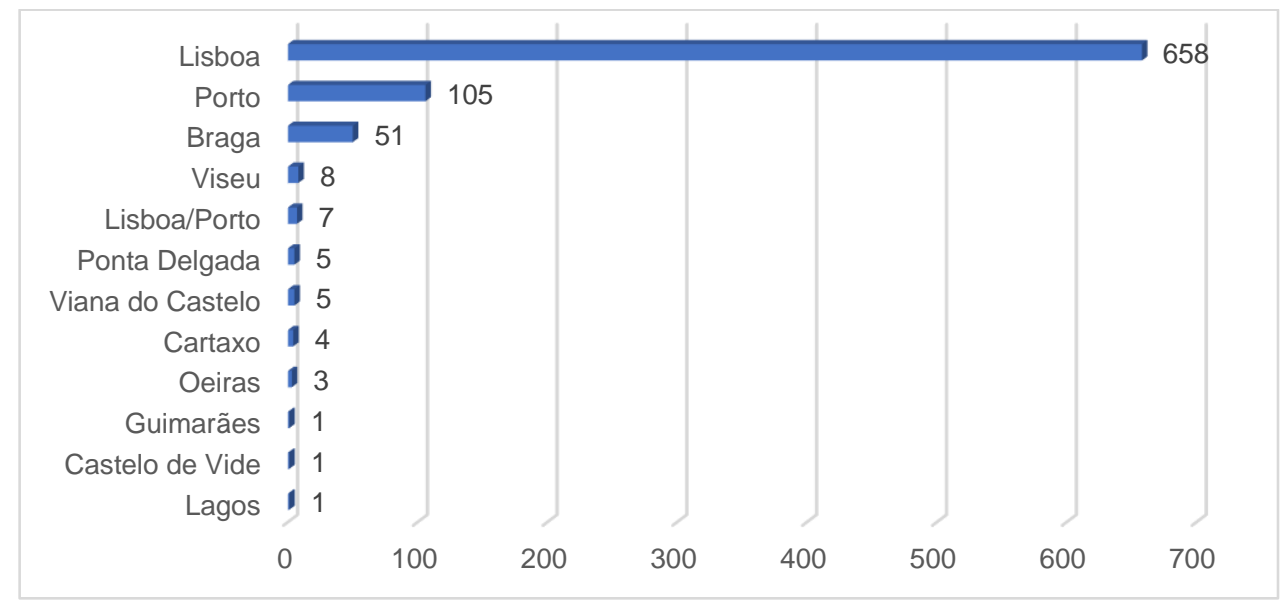

Figura III.2.1: Número de ocorrências por Concelho, entre 2007 e 2017 Fonte: Elaboração própria.

O concelho de Braga regista o terceiro maior número de eventos divulgados pelos média. Este facto deve-se ao espaço GNRation, criado em 2012, no

\footnotetext{
${ }^{158}$ Está-se a considerar os dispositivos mediáticos de impressa escrita: Ípsilon (suplemento semanal sobre cultura/artes do Jornal Público), Time Out (Lisboa e Porto), Revista E(suplemento sobre cultura e atualidade, indexado ao semanário Expresso) e Umbigo Magazine (arte, cultura, moda e lifestyle).
} 
âmbito da Capital Europeia da Juventude, apostado mormente na exploração da música, do vídeo e animação. Esta manifestação explica quase a totalidade da dinâmica artística bracarense espelhada nos média.

Em termos territoriais (Figura III.2.2 que reflete a distribuição das ocorrências por concelhos e NUT III), verifica-se que é a Área Metropolitana de Lisboa a que mais se salienta no contexto de análise, seguindo-se a homóloga do Porto. O destaque do Alto Minho em terceiro lugar explica-se pelo caso já apontado de Braga. A cidade de Viseu (Viseu Dão-Lafões) justifica, na totalidade, as ocorrências registadas nesse território, sobretudo pela manifestação Jardins Efémeros, um festival multidisciplinar (criado em 2011) que tem vindo a consolidar-se como uma iniciativa de relevo no território local/regional, mas também a nível nacional.

\section{Concelho/Municípios}

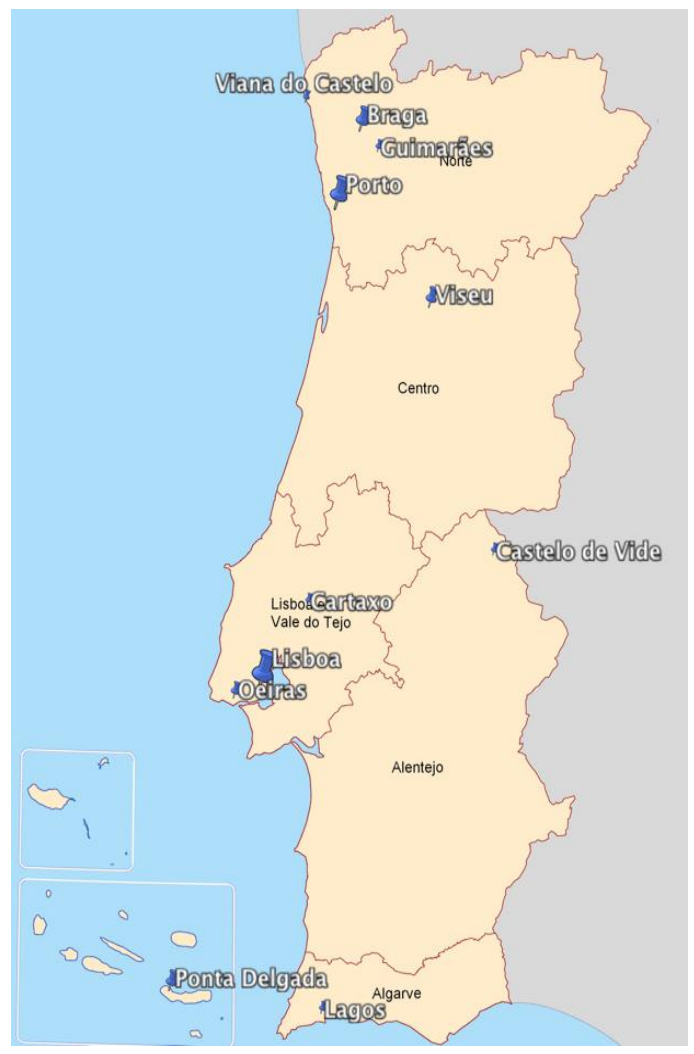

\section{NUT III - Comunidades}

Intermunicipais

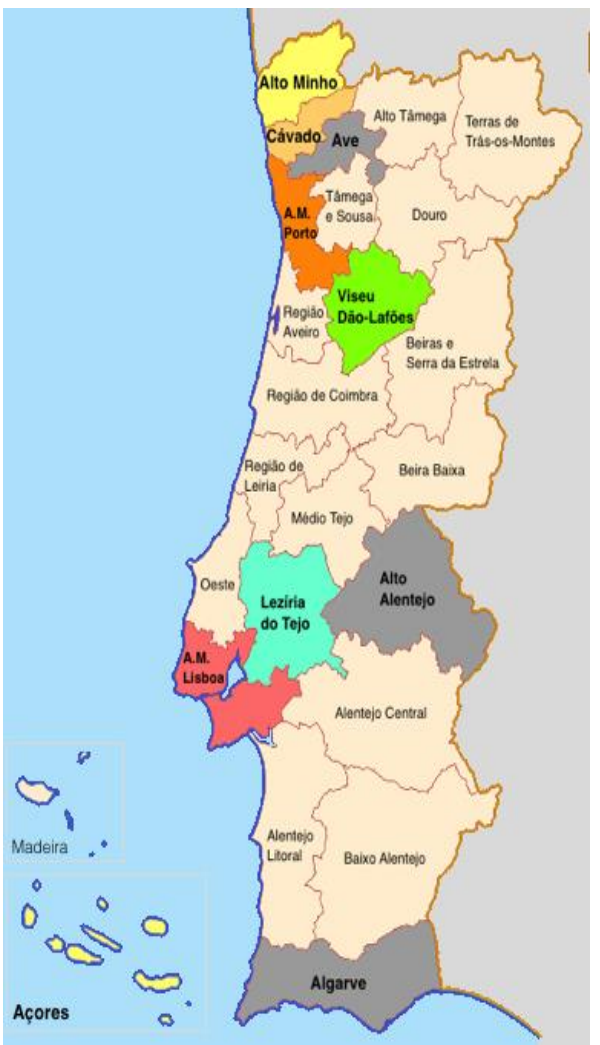

Figuras III.2.2: Mapa das ocorrências, por Concelho e NUT III, entre 2007 e 2017 Fonte: https://pt.wikipedia.org/wiki/NUTS_de_Portugal//(editado).

A manifesta estrutura macrocéfala da realidade sociológica portuguesa evidencia-se claramente pelo facto do maior número de incidências ocorrer em Lisboa e, claro está, na NUT em que se integra. São várias as iniciativas que registamos em Lisboa e nas cidades/concelhos limítrofes. Destas, 
destaca-se a Galeria Zé dos Bois - ZDB, sendo a que, inequivocamente, se assume como a que maior número de referências congrega ao nível dos conteúdos mediáticos considerados. A ZDB é singular no subcampo em estudo, tendo em conta a sua longevidade (mais de 20 anos) e, sobretudo, notoriedade na esfera artística e cultural não só da cidade de Lisboa, mas ao nível regional e nacional. Salienta-se, ainda neste território, o Festival Iminente, cujas duas primeiras edições decorreram em Oeiras e que, em 2018, decorreu na cidade de Lisboa, estando estabelecido manter-se na cidade por mais duas edições. O Iminente caracteriza-se como um movimento criativo que une várias "novas" formas de arte, procurando o estabelecimento de diálogos entre a cultura e arte portuguesas e outras formas de expressão e culturas.

A Norte, a hegemonia cabe ao concelho do Porto. Aqui evidencia-se a manifestação Maus Hábitos, espaço cultural que surge, no início do milénio, como alternativo no campo artístico portuense; transdisciplinar por natureza, promove iniciativas de apoio à produção, de mediação e divulgação artísticas, tendo vindo a inscrever-se de forma notória no roteiro artístico e cultural da cidade. No Centro do país, os Jardins Efémeros constituem a manifestação com maior destaque conferido pelos dispositivos mediáticos analisados, como vimos. No sul do país, o LAC - Laboratório de Artes Criativas é o que melhor representará as manifestações em estudo; é uma associação cultural sem fins lucrativos, formada em 1995 por um grupo de pessoas das mais diversas áreas artísticas. Na Região Autónoma dos Açores, o Festival Walk\&Talk assume particular relevância. Fundado em 2011, em Ponta Delgada (S. Miguel), autocaracteriza-se como uma plataforma artística transdisciplinar que procura incentivar a criação artística em território açoriano, em partilha e comunicação com "o mundo". Um último apontamento incide no tipo de eventos mais significativos no conjunto das manifestações em estudo e nas áreas artistas mais representadas. Como podemos verificar, na Figura 3, estamos perante uma hegemonia evidente dos concertos. A promoção deste tipo de evento acaba por dominar as ocorrências das manifestações no âmbito dos dispositivos mediáticos em estudo. Na verdade, espaços como a ZDB (Lisboa) e Maus Hábitos (Porto) são, na maioria das vezes, referenciados nos/pelos média a respeito da promoção de um concerto. 


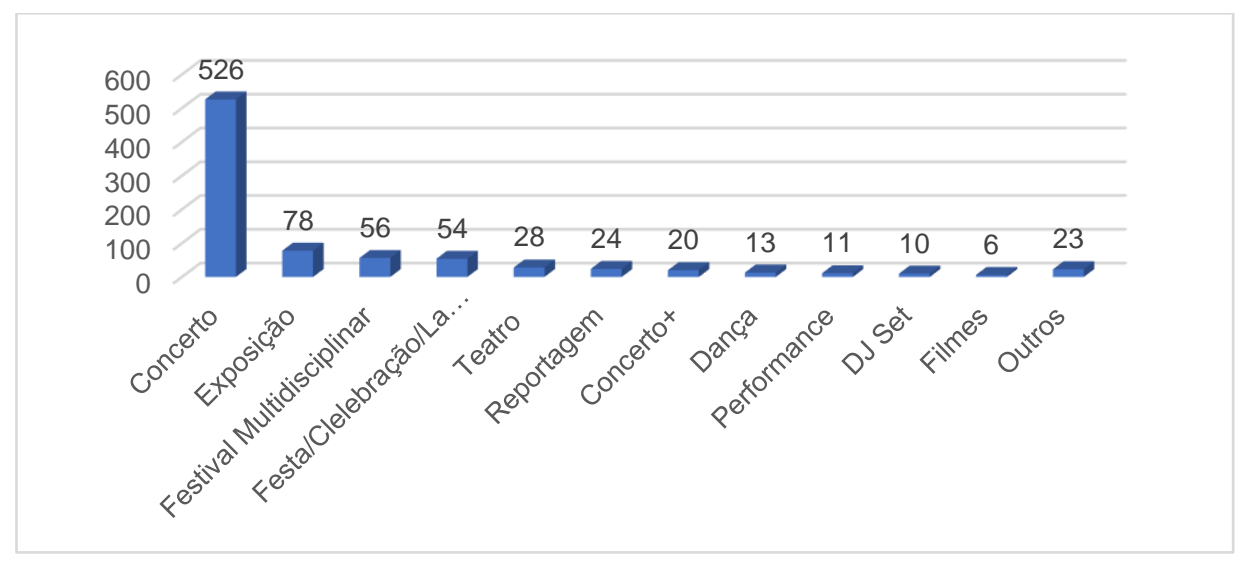

Figura III.2.3: Tipo de eventos/iniciativas promovidos no âmbito das manifestações artísticas alternativas, entre 2007 e 2017

Fonte: Elaboração própria.

Em termos de áreas artísticas, destaca-se a música, seguindo-se as artes visuais e/ou plásticas (patente sobretudo em exposições) e uma dimensão multidisciplinar/transdisciplinar. A figura abaixo espelha a hierarquia dos eventos registados no âmbito da recolha de dados efetuada.

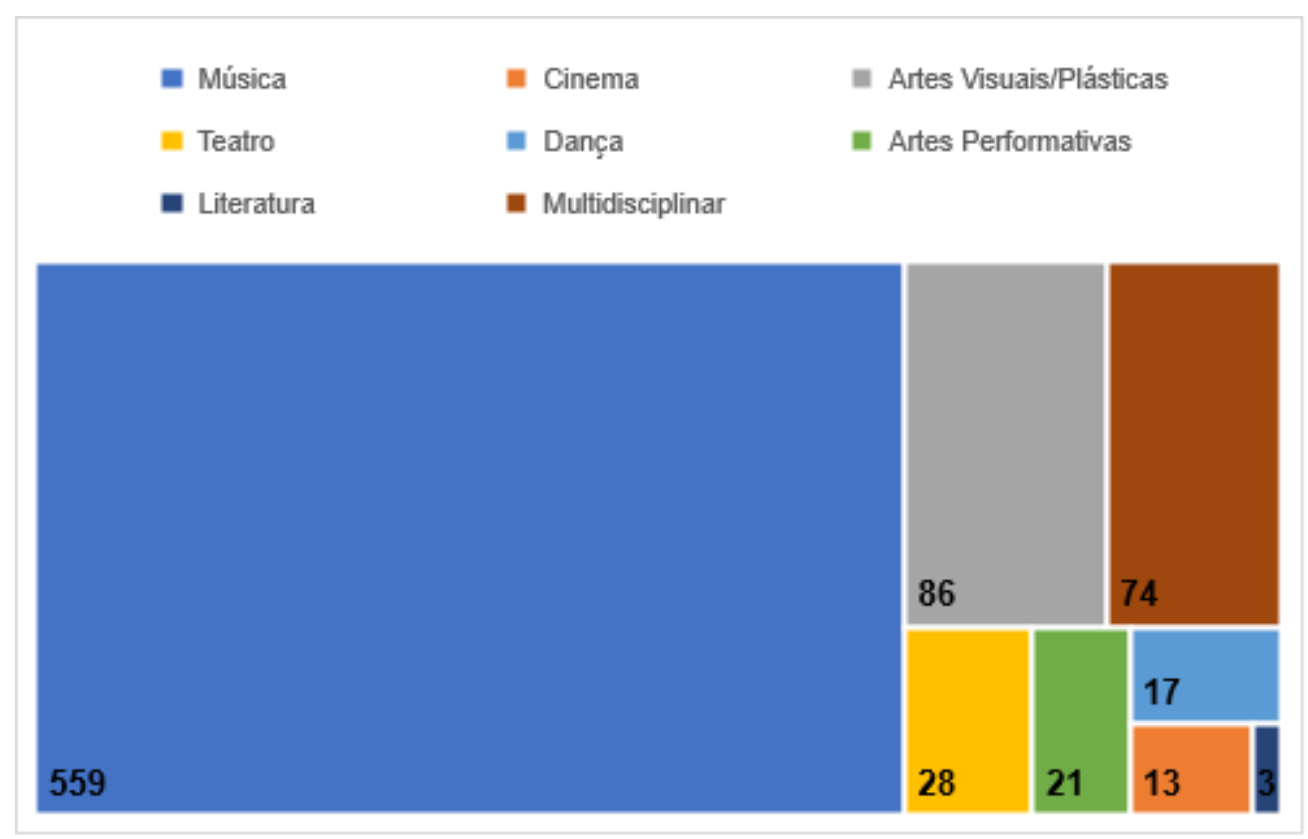

Figura III.2.4: Representação da hierarquia do tipo (área artística) dos eventos promovidos/divulgados, entre 2007 e 2017 Fonte: Elaboração própria.

Esta breve cartografia permite-nos inferir um retrato do subcampo que estamos a estudar, expresso em algumas linhas que passamos a enunciar: a hegemonia (estrutural) dos territórios que integram as cidades de Lisboa e Porto (mais evidente no primeiro caso) no campo artístico e cultural em geral, confirmada pelo subcampo em estudo; estamos perante um subcampo fluído - o que não o distingue da totalidade da realidade sociológica contemporânea 
-, onde a eventual efemeridade da existência se entrelaça com configurações que ultrapassam fronteiras, entrecruzam processos, lógicas e artes diversificadas; a hegemonia da música, que pode ser explicada, em parte, pelo processo que alguns evidenciam como característica das sociedades contemporâneas e que designam por "festivalização" da cultura, mas no sentido amplo, abrangendo a própria vivência do quotidiano (Bennet, 2005), assumindo precisamente a música, neste processo, um papel primordial, não só pela ideia de festival lhe estar subjacente, como também pelo facto de se constituir como campo indelével da popularização da cultura, da demarcação de grupos sociais que consubstanciam modos e estilos de vida diferenciadores e distintivos, simultaneamente disruptivos e persuasivos; a tendência em verificar-se o efeito de gatekeeping, que traduzirá a significância das ocorrências e respetiva correlação com o destaque de algumas manifestações (coloca-se a questão de perceber se estamos perante manifestações com uma programação mais intensa ou se, já num patamar de consagração, são as que mais atenção captam por parte dos media ou, ainda, se estamos perante a junção das duas dimensões).

\section{Esboço de uma alternância reflexiva em torno de considerações fluentes}

Da nossa reflexão resulta estarmos perante espaços sociais e simbólicos uma vez artísticos e culturais - que, independentemente da sua territorialidade e materialização física, vão-se esculpindo, na própria medida da sociedade contemporânea, como híbridos e por tal revestidos de uma fluidez adequada aos tempos líquidos que vivemos. Defendemos a configuração de um subcampo específico - ao nível de artistas, das criações artísticas, dos processos e lógicas determinadas - cujas manifestações concretas que integra invocam à diluição da sua especificidade, devido, precisamente, à fluidez assinalada. Os processos tangenciais que atravessam estas manifestações transformam-nas, ao longo do tempo e inerentemente à sua consolidação, em entidades/estruturas/iniciativas que tendem à sua própria institucionalização (seja ela visível nos processos de canonização próprios do campo, seja pela tendência, digamos assim, para a mercadorização da produção e usufruição artísticas), rompendo com noções mais puristas que fundamentariam de forma mais inequívoca a sua concetualização. Por isso se procurou discutir os conceitos que gravitam em torno deste subcampo. 
Não consideramos que estar perante uma amálgama predisposta a diluir-se uma fatalidade, antes um desafio. Este radica na essencialidade do que estamos a considerar e, sobretudo, nas características e especificidades que são próprias do conjunto de manifestações que nos preocupa estudar, quer na sua origem, quer na sua continuidade. A consolidação das mesmas depende - tal como todos os outros movimentos sociais - de uma certa institucionalização; de outro modo a sua sobrevivência social não seria possível. E o seu reconhecimento pelas estruturas de informação e conhecimento comprovam-no, ao demarcar, nos territórios, a sua existência e, invariavelmente, o seu reconhecimento e consagração.

Uma das especificidades que salientamos nestas manifestações constituirá uma dimensão crucial na construção da sua identidade - uma tendência seguramente democratizadora ao privilegiar, na base, o encontro entre o público e a criação artística. Aqui também radicará explicação para a continuidade deste tipo de manifestações, mormente os casos que se mantêm e se destacam nos territórios estruturalmente inóspitos e sobrevivos do Portugal contemporâneo.

\section{Referências Bibliográficas}

Bauman, Z. (2013). A cultura no mundo líquido moderno. Rio de Janeiro: Zahar.

Becker, H. S. (1984). Art worlds. London: University of California Press.

Bennet, A. (2005). Culture and Everyday Life. London: Sage Publications.

Bennett, A. \& Peterson, R. A. (2004). Music scenes: local, translocal and virtual. Nashville: Vanderbilt University Press.

Blum, A. (2001). Scenes. Public, pp. 7-35.

Bourdieu, P. (2003). Questões de sociologia. Lisboa: Fim de Século Edições.

Bourdieu, P. (1996). As regras da arte. Lisboa: Editorial Presença.

Chaney, D. C. (1994). The cultural turn: scene-setting essays on contemporary cultural history. London: Routledge.

Costa, P. (2002). As atividades da cultura e a competitividade territorial: o caso da Área Metropolitana de Lisboa. Lisboa: Instituto Superior de Economia e Gestão.

Crane, D. (1992). The production of culture - Media and the urban arts. Newbury Park/London/New Deli: Sage Publications. 
DGARTES. (2018). Modelo de Apoio às Artes - Programa de Apoio Sustentado. Ciclo 2018-2021. Principais Resultados. Lisboa: Direção Geral das Artes.

Fortuna, C. \& Leite, R. P. (2009). Plural de cidade: Novos léxicos urbanos. Coimbra: Almedina.

ICS -UL. (2014). Mapear os recursos, Levantamento da legislação, Caracterização dos atores, Comparação internacional. Lisboa: GEPAC/SEC.

Guerra, P. \& Straw, W. (2017). I wanna be your punk: o universo de possíveis do punk, do D.I.Y. e das culturas underground. Cardernos de Arte e Antropologia, 6, no 1, pp. 516.

Guerra, P. \& Costa, P. (eds) (2016). Redefining art worlds in the late modernity. Porto: Universidade do Porto. Faculdade de Letras.

Guerra, P. \& Quintela, P. (2016). From Coimbra to London: to live the punk dream and 'meet my tribe'. Em J. Sardinha, \& R. Campos (orgs), Transglobal sounds: Music, Youth and Migration (pp. 31-50). New York/London: Bloombury Publishing.

Guerra, P. (2013). Punk, ação e contradição em Portugal. Uma aproximação às culturas juvenis contemporâneas. Revista Crítica de Ciências Sociais, 102, pp. 111-134.

Guerra, P. (2018). Raw Power: Punk, DIY and underground cultures as spaces of resistance in contemporary Portugal. Cultural Sociology, 12(2), pp. 241-259.

Jürgens, S. V. (2016). Instalações provisórias - independência, autonomia, alternativa e informalidade. Artistas e exposições em Portugal no séc. XX. Lisboa: Sistema Solar|Documenta.

Jauss, H. R. (1990). Pour une esthétique de la réception. Paris: Galimard.

Latour, B. (1994). Jamais fomos modernos. Rio de Janeiro: Editora 34.

Silva, A. S., Babo, E. P. \& Guerra, P. (2015). Políticas culturais locais: contributos para um modelo de análise. Sociologia, Problemas e Práticas, 78, pp. 105-124.

Straw, W. (1991). Systems of articulation, logics of change: communities and scenes in popular music. Cultural Studies [em linha] [Out. 1991]. 